\title{
AS GRAVURAS RUPESTRES NA REGIÃO SERRANA DOS MUNICÍPIOS DE FRANCISCO DANTAS E PORTALEGRE, NA MICRORREGIÃO DE PAU DOS FERROS, RIO GRANDE DO NORTE, BRASIL
}

\author{
Alano Jaciguara Dantas de \\ Alencar Martins*
}

Valdeci dos Santos Júnior**
RESUMO: Na microrregião geográfica de Pau dos Ferros, no Estado do Rio Grande do Norte, sete municípios possuem sítios arqueológicos com gravuras rupestres. Dois desses, Francisco Dantas e Portalegre, estão situados entre 500 a $700 \mathrm{~m}$ de altitude. Essa pesquisa está direcionada para análise das gravuras rupestres existentes nos sítios arqueológicos (Congo I, Congo II, Congo III, Furna do Noberto, Ancoreta, Furna do Letreiro e Furna do Pelado) localizados em duas unidades geomorfológicas serranas naqueles municípios: a Serra de Portalegre e a Serra da Madalena. Devido às premissas observadas de semelhanças nas temáticas, nos suportes rochosos e da utilização das mesmas técnicas de execução das gravuras rupestres, esse trabalho visa responder ao questionamento: Os autores das gravuras rupestres naquelas localidades possuíam o mesmo padrão de assentamento? Para a consecução desse objetivo, foram efetuadas pesquisas bibliográficas e imagéticas, elaboração de mapas e estudos comparativos de temáticas/ técnicas de execução das gravuras rupestres. Os resultados apontam que a escolha dos autores pela técnica de gravura, pode estar associada à disponibilidade da litologia do suporte rochoso, sendo provável que exista uma relação entre o posicionamento geomorfológico dos sítios em altas vertentes e a existência de fontes d'agua no entorno, caracterizando um mesmo padrão de assentamento pretérito para todos os sítios do conjunto da pesquisa.

Palavras-chave: Paisagem, Assentamento, gravuras rupestres.

ABSTRACT: In the geographic microregion of Pau dos Ferros, in the State of Rio Grande do Norte, seven municipalities have archaeological sites with rock engravings. Two of these, Francisco Dantas and Portalegre, are located between 500 and $700 \mathrm{~m}$ of altitude. (Congo I, Congo II, Congo III, Furna do Noberto, Ancoreta, Furna do Letreiro and Furna do Pelado) are located in two mountainous geomorphological units in these municipalities: Serra de Portalegre and the Serra da Madalena. Due to the observed premises of similarities in the themes, the rock supports and the use of the same techniques of execution of the rock engravings, this work aims to answer the question: Do the authors of rock engravings in those localities have the same pattern of settlement? In order to achieve this objective, bibliographical and imagery researches, mapping and comparative studies of the themes / techniques for the execution of rock engravings were carried out. The results point out that the authors' choice for the engraving technique may be associated to the availability of the lithology of the rocky support, and it is probable that there is a relationship between the geomorphological positioning of the sites in high slopes and the existence of water sources in the surroundings, Characterizing the same past settlement pattern for all sites in the survey set.

Keywords: Archeology of the Landscape, Pattern of settlement, rock engravings. 


\section{Introdução}

A microrregião geográfica de Pau dos Ferros, no Estado do Rio Grande do Norte, está formada por dezessete municípios, onde sete desses (Francisco Dantas, Itaú, José da Penha, Marcelino Vieira, Portalegre, Tabuleiro Grande e Tenente Ananias) possuem sítios arqueológicos com gravuras rupestres. Dois municípios ${ }^{1}$ desse conjunto, Francisco Dantas e Portalegre, estão situados em contexto geoambiental serrano, com altimetrias médias entre $500 \mathrm{~m}$ a $700 \mathrm{~m}$ nas áreas mais elevadas.

O objeto de estudo desse artigo está direcionado para a análise das gravuras rupestres existentes em sete sítios arqueológicos (Congo I, Congo II, Congo III, Ancoreta, Furna do Noberto, Furna do Letreiro e Furna do Pelado) localizados em duas unidades geomorfológicas serranas existentes nesses dois municípios: a Serra de Portalegre (Portalegre) que possui área aproximada de $128 \mathrm{~km}^{2}$ e a Serra da Madalena (Francisco Dantas) que possui uma área aproximada de $187 \mathrm{~km}^{2}$ (Figura 1).

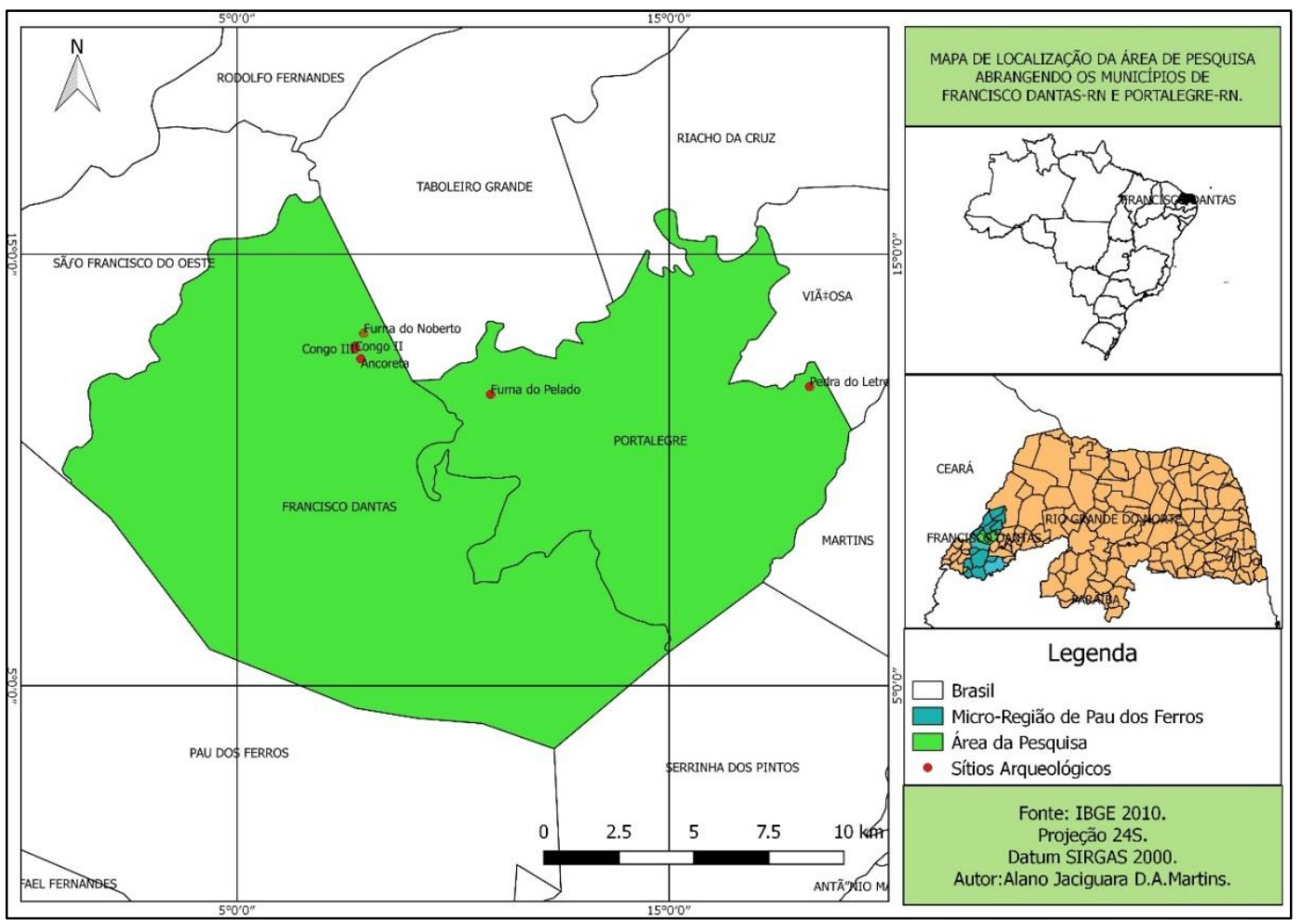

Figura 1 - Mapa de Localização da área de pesquisa. Fonte: IBGE, 2010, modificado por Martins, 2017.

As informações escritas mais antigas sobre a presença de sítios arqueológicos na Serra de Portalegre retroagem ao ano de $1914^{2}$. Já na Serra da Madalena, também conhecida como

\footnotetext{
${ }^{1}$ Relação dos municípios da microrregião geográfica de Pau dos Ferros: Alexandria, Francisco Dantas, Itaú, José da Penha, Marcelino Vieira, Paraná, Pau dos Ferros, Pilões, Portalegre, Rafael Fernandes, Riacho da Cruz, Rodolfo Fernandes, São Francisco do Oeste, Severiano Melo, Taboleiro Grande, Tenente Ananias e Viçosa.

2 Em 20 de Setembro de 1914, o pesquisador Francisco Assis Silva visita a Pedra do Letreiro quando fez a seguinte descrição: "Informado que nas Torres, lugar que dista uns 3 quilômetros da cidade, lado leste, havia algo de misterioso, para lá me dirigi afim de constatar as inscrições porventura existentes num lagedo (a pedra do letreiro). Para vê-lo de perto tive que penetrar numa gruta ou cavidade feita na rocha bruta, onde só se podia entrar
} 
"Serrinha dos Campos", freis José Lima e Peregrino visitaram o sítio arqueológico Congo I em 1941 , onde colocaram um tipo de tinta branca no interior dos sulcos das gravuras rupestres efetuados no suporte arenítico, na tentativa de visualizar melhor os registros simbólicos, além de colocar data da visita deles ao local (Martins, 2001).

Devido às premissas observadas de semelhanças temáticas, de escolhas de suportes rochosos e de mesma utilização de técnicas de execução das gravuras rupestres, esse trabalho visa responder ao seguinte questionamento: Os grupos humanos pretéritos que elaboraram as gravuras rupestres nos municípios de Portalegre e Francisco Dantas tinham o mesmo padrão de assentamento?

\section{Procedimentos teóricos - metodológicos}

Para entender a inserção dos sítios arqueológicos com gravuras rupestres nas áreas da pesquisa foi necessário trabalhar, de forma multidisciplinar, com os conceitos de arqueologia da paisagem e padrão de assentamento.

A Arqueologia da Paisagem procura utilizar as ferramentas das geociências para entender os processos de ocupação dos espaços pelos grupos humanos e como essa interação recíproca modifica a própria paisagem natural, que passa a ser socialmente construída. Essa paisagem seria a união de objetos naturais, (fruto da natureza) e objetos fabricados (objetos sociais testemunhos das atividades humanas pretéritas e contemporâneas) (Fagundes, 2008; Santos Júnior, 2013).

A necessidade de relacionar o homem e o meio ambiente, fez com que a pesquisa arqueológica passasse a relacionar os vestígios culturais e sítios arqueológicos aos elementos naturais do mundo que os rodeia, entendendo a paisagem como um conjunto de elementos frutos do constante relacionamento entre homens e meio. Essa paisagem passa a ser modificada constantemente e é passível de ser analisada como um artefato que se enquadra em seu campo de investigação

A localização nessa paisagem de sítios portadores de gravuras rupestres auxilia no entendimento da interação entre os grupos humanos pré-históricos e seus ambientes permitindo, dessa forma, uma análise "dos possíveis critérios de acordo com os quais uma comunidade decidiu habitar ou escolher determinado ponto concreto da paisagem" (Mutzemberg apud Hyder, 2004, p.19). Dessa forma é necessário identificar padrões de assentamentos $^{3}$ pelos grupos pretéritos na utilização dessa paisagem natural, procurando

deitado, por uma apertada passagem. Não obstante, e ávido por copiar ou decifrar o enigma do tesouro, ali penetrei. A abertura da gruta, pelo lado do nascente, alargava-se, deixando vê o panorama longínquo do sertão imenso e o imenso abismo que ali mesmo começava. Confesso com franqueza que não seria eu dos primeiros a entrar naquela morada de gatos e mocós, tamanho o risco que se me apresentava. Mas, depois que vi mergulhar três dos meus companheiros de averiguações na gruta histórica (Gabriel de Souza, Antônio de Zé Pedro e Joca Macário), não vacilei por mais tempo. Fui o quarto dos visitantes da pequena caverna que, apesar de oferecer estreitas entrada, interiormente era abobadada, facilitando, assim, o movimento corporal dos improvisados trogloditas. Nada ví de extraordinário e digno de especial menção. Porém o que tenho a revelar é que numa das paredes laterais da gruta, estavam visivelmente delineados uns traços ou sinais que tinham certa analogia com o nosso m e n." (Silva, Francisco de Assis, 1953. Boletim Bibliográfico da Biblioteca Pública Municipal de Mossoró e do Museu Municipal de Mossoró. Ano IV, número 44, cidade de Mossoró-RN, publicado em 31 de Janeiro de 1952 e impresso em Junho de 1953, páginas 22 e 23)

${ }^{3}$ Uma das definições do conceito de padrão de assentamento pode ser entendida como: "a distribuição de sítios arqueológicos em determinada área geográfica, refletindo as relações das comunidades do passado com o meio ambiente e as relações entre elas próprias no seu contexto ambiental, 
observar essa articulação de cada um desses sítios em relação ao conjunto de sítios existentes em um determinado contexto geoambiental, por meio da semelhança dos atributos culturais e pela própria relação espacial existente entre eles, visando inferir padrões de distribuição e localização dos sítios em relação aos compartimentos da paisagem para, a partir daí, caracterizar e organizar as unidades que fazem parte do sistema de assentamento ${ }^{4}$. Nesse sentido, o padrão de assentamento seriam as relações geográficas e fisiográficas de um grupo de sítios de uma determinada cultura, já o sistema de assentamento seriam as relações funcionais entre os sítios inseridos em um determinado padrão (Lanata, 1993).

A identificação desses padrões de assentamentos permite desvendar, ainda que parcialmente, critérios utilizados para apropriação dessa paisagem natural pelo homem pretérito, considerando que ela possa ter sofrido alterações desde a época em que as pinturas e gravuras foram realizadas. Dessa forma, ao se observar os sítios com gravuras rupestres, é possível levantar inferências com relação aos possíveis critérios de escolhas dos autores quanto ao local aonde pintar e o que deveria ser representado, sempre levando em conta as relações entre os grafismos e as feições ambientais (Isnardis, 2015).

Para a consecução desse objetivo, foram efetuadas pesquisas bibliográficas e imagéticas com relação ao conjunto de sítios pesquisados. Foi desenvolvida a análise cartográfica e elaborações de mapas, além da coleta de dados litológicos e ambientais, bem como realizadas medições e análises em laboratório através de estudos comparativos de temáticas e técnicas de execução das gravuras rupestres dos sítios pesquisados.

\section{Caracterização geoambiental da área da pesquisa}

No sentido geológico, as Serras de Portalegre e a da Madalena estão inseridas na província Borborema, sendo formada por litotipos dos Complexos Jaguaretama (PP2j), das Suítes Poço da Cruz (PP3/pc) e Calcialcalina de Médio e Alto Potássio Itaporanga (PP3/pc), bem como pelos depósitos Colúvio-eluviais (NQc) (CPRM, 2005).

As Unidades Litoestratigráficas representadas naquela área correspondem a terrenos do Cenozoico (Formação Serra dos Martins $(\mathrm{sm})$ : arenito médio a conglomerático), do Neoproterozoico (Suíte Calcialcalina de Médio a Alto Potássio Itaporanga $(\mathrm{cm})$ : granito e granodiorito porfirítico associado a diorito (588 Ma U-Pb) e do Paleoproterozoico (Complexo Jaguaretama (j): ortognaisse migmatizado tonalítico a granodiorítico e granítico, migmatito, restos de supracrustais). Assim como nas demais serras do Rio Grande do Norte, as formações rochosas (Figuras 2 e 3) existentes em seus topos estão caracterizados por arenitos médios a conglomeráticos (CPRM, 2005).

\footnotetext{
onde estratégias de subsistência, estruturas políticas e sociais e densidade da população foram alguns dos fatores que influenciaram a distribuição do povoamento, desenhando os padrões de assentamento" (Morais, 2000, p.202).

${ }^{4}$ A importância da compreensão dessas diferentes formas de assentamento em uma determinada área permite vislumbrar as relações que eventualmente possam existir entre eles. Com esse procedimento, esta perspectiva não fica restrita à ideia de um sítio isoladamente, mas procura observar de que forma os vários tipos de sítios estão articulados, fazendo parte de um todo, constituindo, portanto, um Siste ma de Assentamento (Beber, 2004, p.133).
} 
O relevo evidencia a maior parte de seu território representada por um conjunto serrano formado pelas Serra da Madalena e de Portalegre, possuindo uma altitude média entre $700 \mathrm{~m}$ e 800 m (Moraes, 1977). A sua hidrografia está inserida na bacia do Rio Apodi-Mossoró (Camacho, 2014).

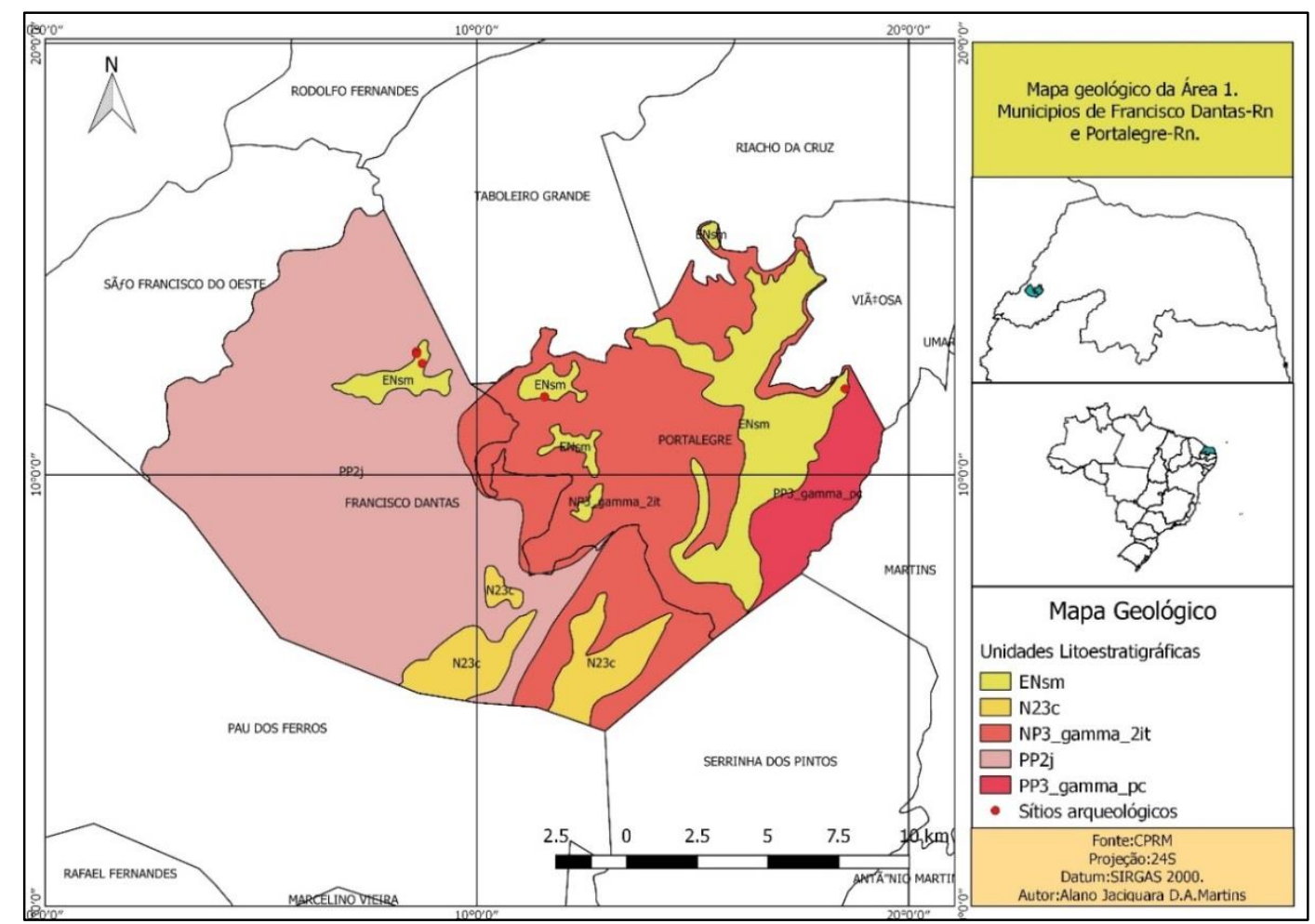

Figura 2. Mapa Geológico da área de pesquisa. Fonte; IBGE, 2010. Adaptado por Martins, 2017.

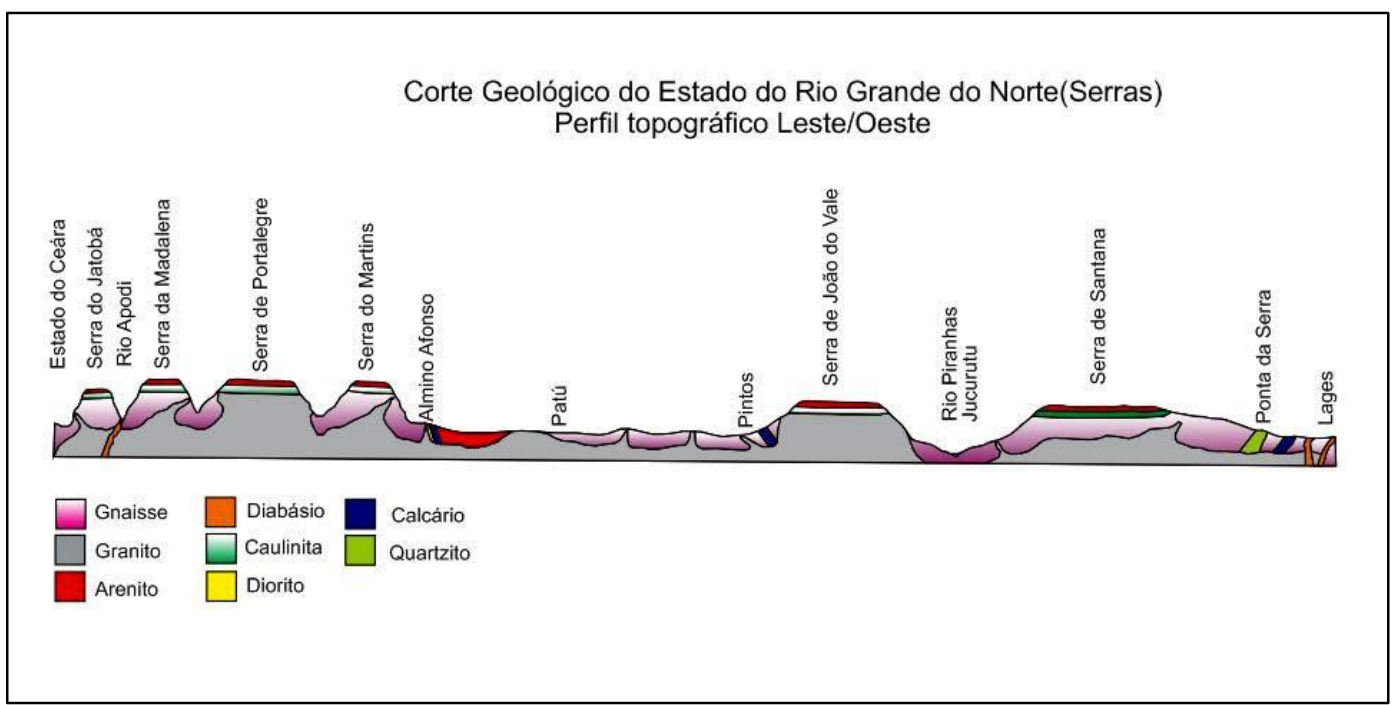

Figura 3. Corte geológico do Estado do Rio Grande do Norte - perfil topográfico - sentido Leste - Oeste. Fonte: Moraes, 1977. Adaptado por Martins, 2017. 


\section{Caracterização dos sítios arqueológicos}

Para se entender o contexto de posicionamento espacial dos sítios arqueológicos da área da pesquisa, foi necessário efetuar a caracterização de cada um deles, a saber:

\section{Sítio Arqueológico Congo I}

É um abrigo sob rocha arenítica, inserido na Serra da Madalena, situado a $617 \mathrm{~m}$ de altitude e está posicionado em alta vertente (Figura 4). Possui uma leve inclinação da parede do fundo, o que permite a sua utilização como abrigo, evitando a exposição direta as chuvas e ventos (figura 5). No suporte rochoso foram elaboradas gravuras com as técnicas de raspagem ${ }^{5}$ e picotagem $^{6}$, com predominância de grafismos abstratos ${ }^{7}$, com traços retilíneos e curvilíneos, além da presença de cúpules, ocupando uma superfície de $54 \mathrm{~m}^{2}$, com orientação N-SW e abertura voltada para o Oeste (Figuras 6 e 7).

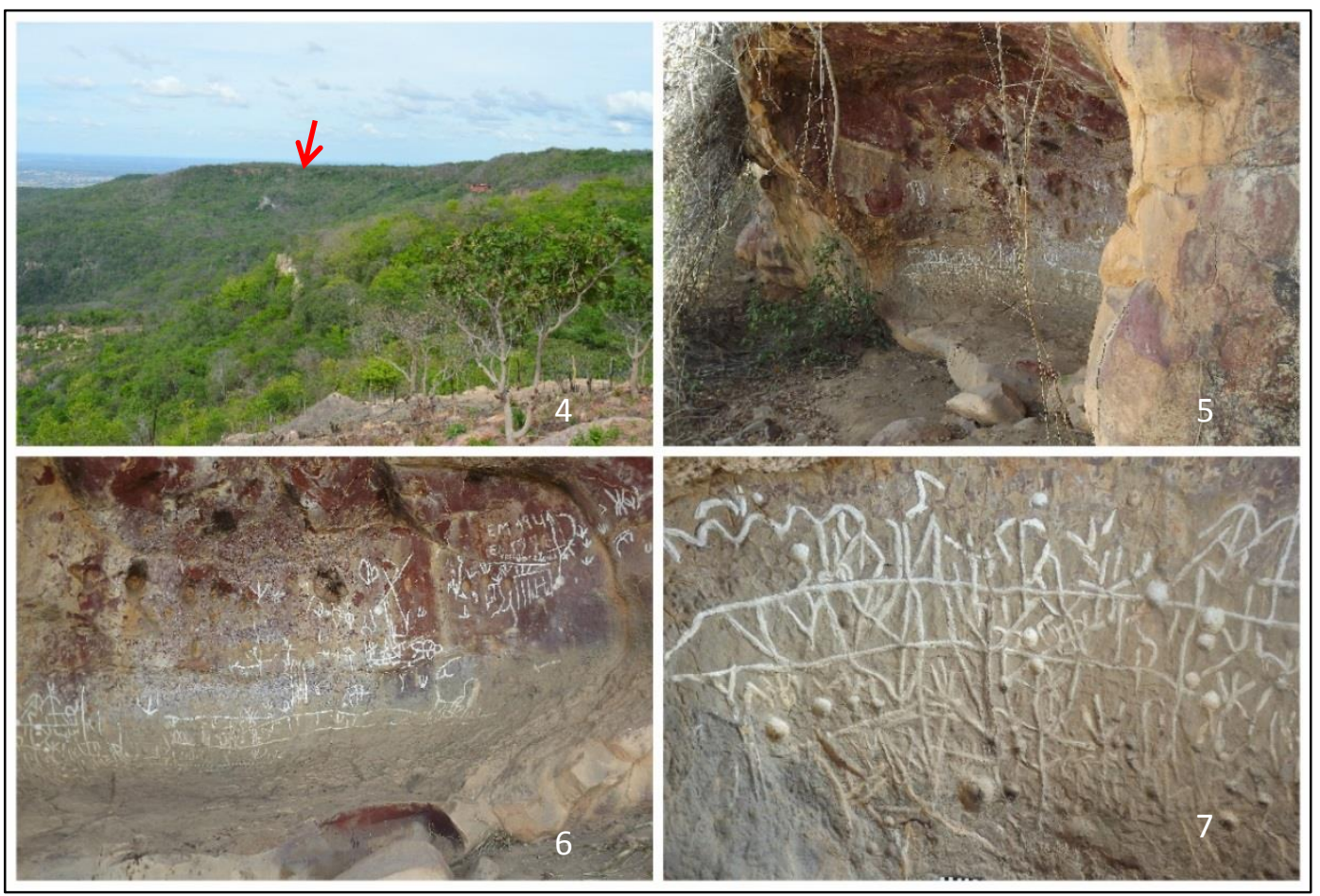

Figuras 4, 5, 6 e 7 -Contexto geoambiental em abrigo arenítico em alta vertente; gravuras rupestres em abrigo arenítico; técnicas de execução por raspagem e picotagem; grafismos abstratos; presença de alinhamento de cúpules e adição de tinta branca no período contemporâneo - Sítio Arqueológico Congo I - Serra da Madalena - Francisco Dantas - RN. Fonte: Martins, 2017.

\footnotetext{
${ }^{5}$ A raspagem seria oriunda de um gesto que aplica contato superficial entre dois corpos, em sentido unidirecional ou bidirecional, isto é, a mão que empunha o instrumento abrasivo executa movimentos num único sentido ou em dois (ida e volta), que deixa visíveis irregularida des nas bordas e no interior dos sulcos, oriundas da textura natural da rocha ou de percussão, quando precedida por esta. Além de ser pouco repetitivo, demandar pouco tempo de trabalho e ser executado através de contato direto de duas superfícies atritantes. (Santos Júnior, 2008).

${ }^{6} \mathrm{~A}$ técnica da picotagem abrange posturas corporais na manufatura das gravuras onde os traços retilíneos ou curvilíneos são obtidos por percussão direta contínua realizados com percutores rochosos ou metálicos com pontas (Santos Júnior, 2008).

7 “...os grafismos desprovidos de traços de identificação reconhecíveis, propriedade denominada na literatura arqueológica de esquemática, abstrata ou grafismos puros. (Cisneiros, 2008. p.111).
} 


\section{Sítio Arqueológico Congo II}

Está também situado na Serra da Madalena, nas proximidades do sítio arqueológico Congo I (90 $\mathrm{m}$ na direção $\mathrm{N}$ ), onde existe um suporte rochoso arenítico, que possui uma inclinação, permitindo assim, a sua utilização como abrigo, evitando a exposição direta as chuvas e ventos; possui $611 \mathrm{~m}$ de altitude e está posicionado em alta vertente (Figura 8).

Nesse suporte rochoso (Figura 9) foram elaboradas gravuras com a concomitância das técnicas de raspagem e picotagem. Embora apareçam raras representações figurativas isoladas (Figura 10), a predominância é de grafismos abstratos, com a repetição de traços retilíneos e curvilíneos já identificados no sítio arqueológico Congo I, assim como a presença de cúpules em alinhamentos horizontais (Figura 11), ocupando uma superfície aproximada de $100 \mathrm{~m}^{2}$, com orientação N-S e abertura voltada para o Oeste. Esse sítio apresenta sedimentos em sua área abrigada, onde se observa uma área com acúmulo de sedimentos e gravuras semienterradas recobertas sendo passível, futuramente, de escavações arqueológicas.

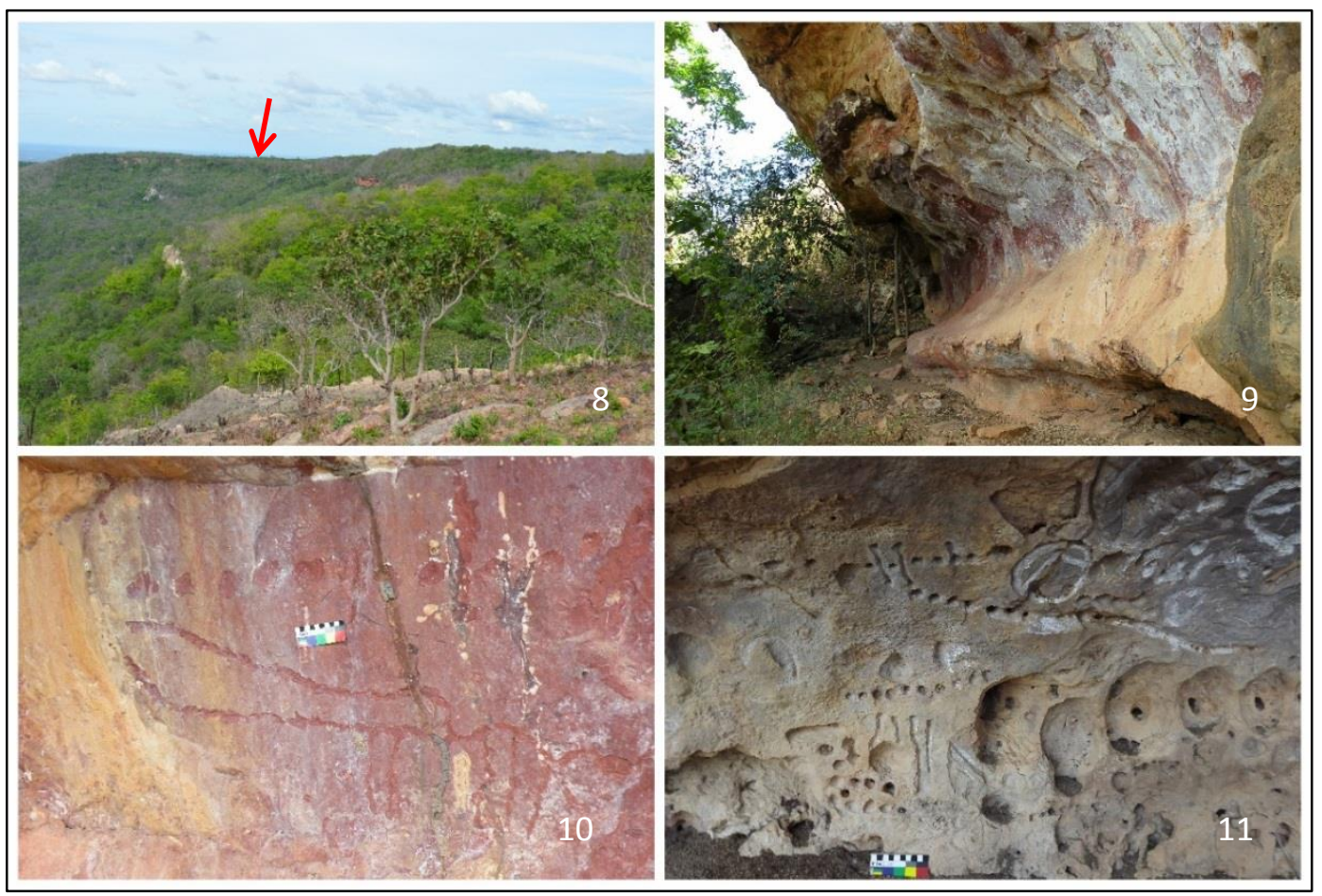

Figuras 8, 9, 10 e 11. Contexto geoambiental em abrigo arenítico em alta vertente; técnicas de execução por raspagem e picotagem; grafismos abstratos; presença de alinhamento de cúpules e adição de tinta branca no período contemporâneo - Sítio Arqueológico Congo II - Serra da Madalena - Francisco Dantas RN. Fonte: Santos Júnior, 2014; Martins, 2016.

\section{Sítio Congo III}

Está situado na Serra da Madalena, nas proximidades do sítio arqueológico Congo I ( $27 \mathrm{~m}$ na direção SW), onde é possível observar um suporte rochoso arenítico que serve como abrigo, evitando a exposição direta as chuvas e ventos; possui $616 \mathrm{~m}$ de altitude e está posicionado em alta vertente (Figura 12). 
No interior do abrigo rochoso (Figura 13), também foram elaboradas gravuras com as técnicas de raspagem e picotagem, onde foi observada a predominância de grafismos abstratos, com morfologias efetuadas por meio de traços retilíneos e curvilíneos (Figuras 14) e cúpules. Os grafismos estão espalhados em diversos setores do abrigo e ocupam uma superfície aproximada de $36 \mathrm{~m}^{2}$, com orientação N-SW e abertura voltada para o Oeste. Boa parte da área do sítio possui sedimentos em seu espaço abrigado, inclusive com gravuras semienterradas (Figura 15), sendo passível de futuras escavações arqueológicas.

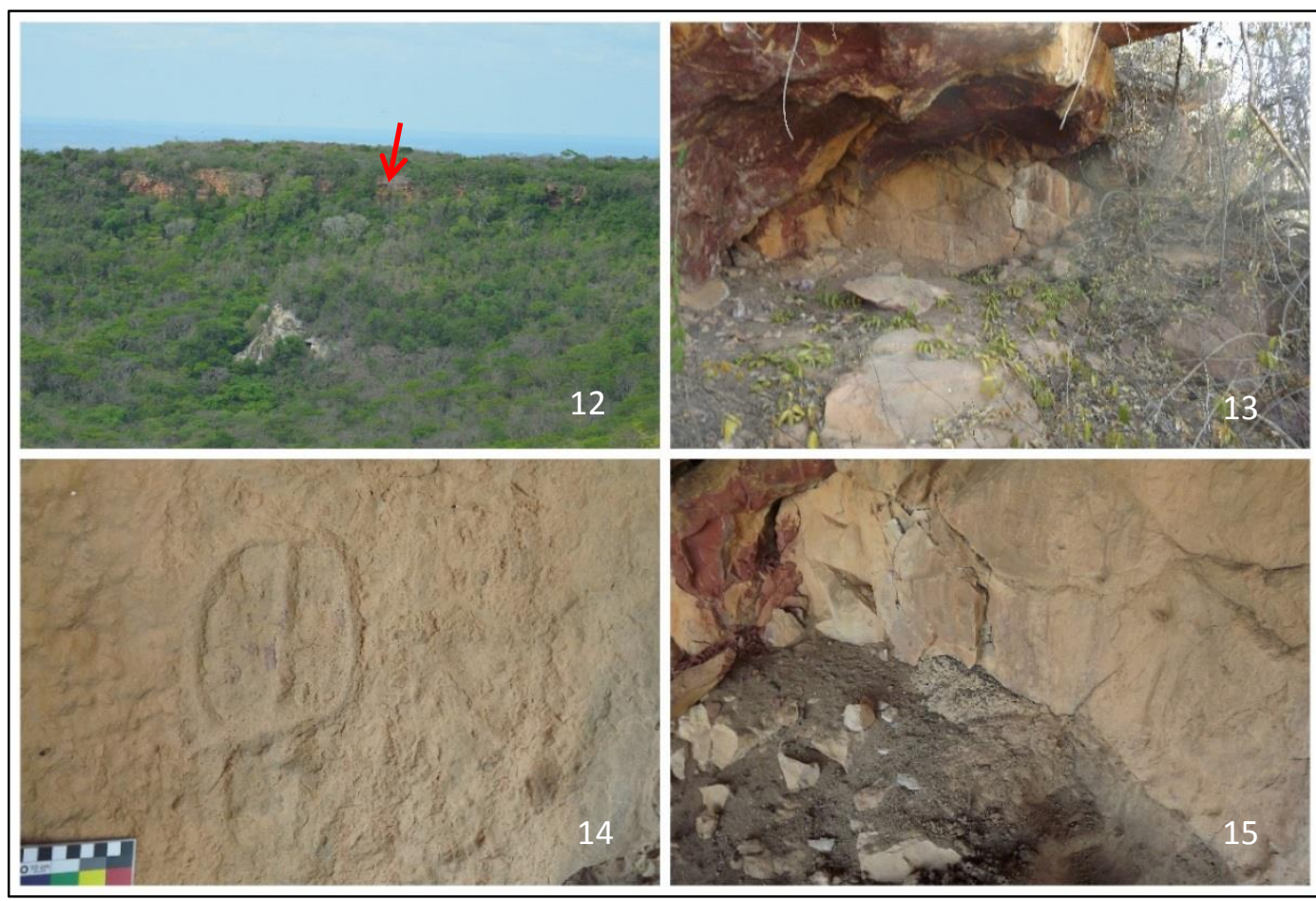

Figuras 12, 13, 14 e 15 - Contexto geoambiental de abrigo arenítico em alta vertente; técnicas de execução por raspagem e picotagem; grafismos abstratos; área com presença de sedimentos que pode permitir escavação arqueológica - Sítio Arqueológico Congo III - Serra da Madalena - Francisco Dantas RN. Fonte: Martins, 2017; Santos Júnior, 2016.

\section{Sítio Ancoreta}

É um abrigo sob rocha arenítica, inserido na Serra da Madalena, situado a $616 \mathrm{~m}$ de altitude, que está posicionado em alta vertente (Figura 16). Possui uma leve inclinação da parede do fundo, o que permite a sua utilização como abrigo, evitando a exposição direta as chuvas e ventos (Figura 17). No suporte rochoso as gravuras foram elaboradas com a técnica de raspagem (Figura 18) e pintura (Figura 19), com predomínio de traços geométricos, círculos e sequências de cúpules. Elas ocupam uma superfície de $80 \mathrm{~m}^{2}$. Sua orientação é $\mathrm{NE}-\mathrm{SE}$ e abertura voltada para Leste.

Assim como os Sítios Congo I e III, que estão localizados a uma distância de 360 m (linha reta), na direção NW, os seus grafismos foram parcialmente "recobertos" por corante na cor branca, possivelmente tendo como matéria-prima a cal. 


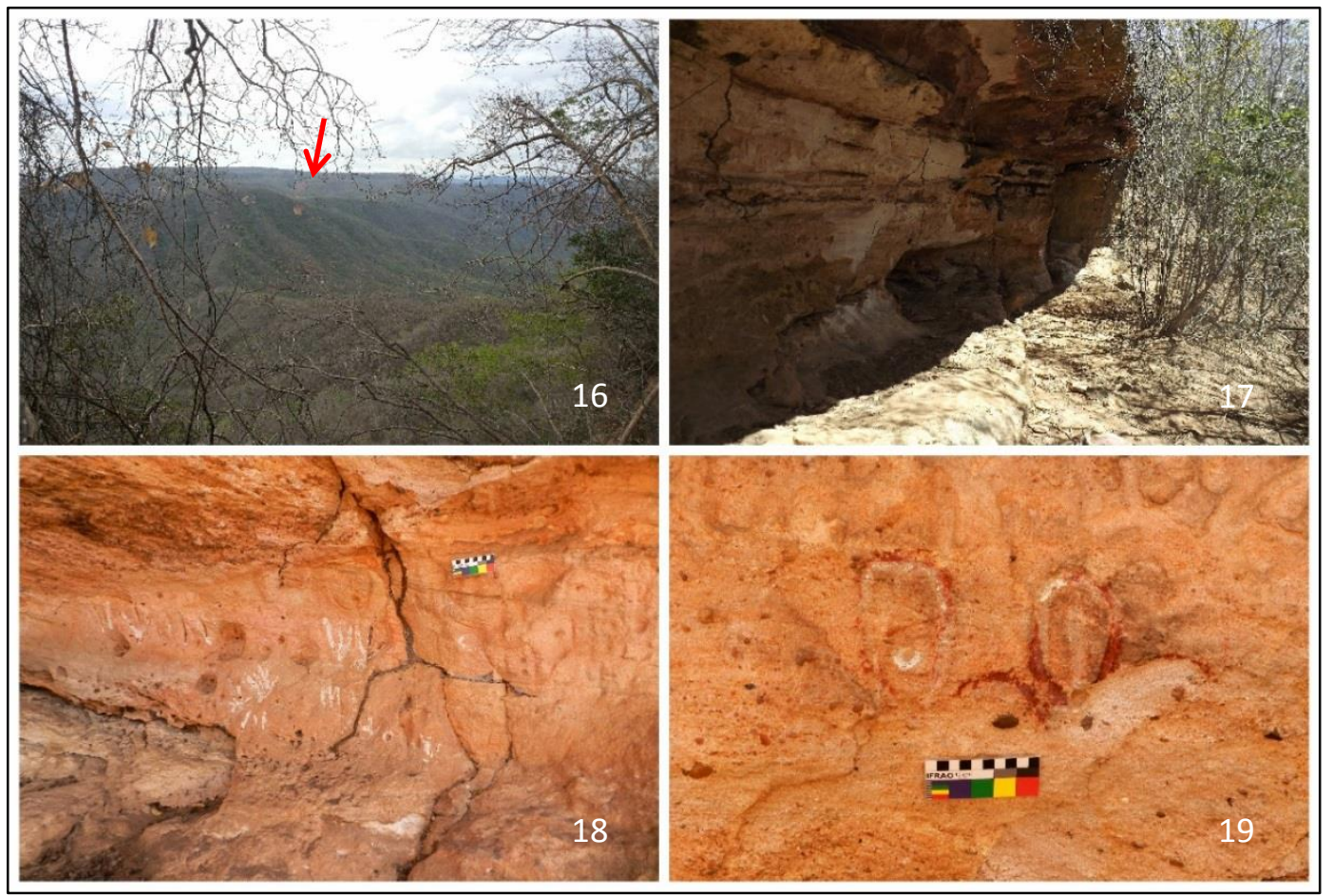

Figuras 16, 17, 18 e 19 - Contexto geoambiental em abrigo arenítico em alta vertente; técnicas de execução por raspagem e picotagem; grafismos abstratos; presença de alinhamento de cúpules e adição de tinta branca no período contemporâneo - Sítio Arqueológico Ancoreta - Serra da Madalena - Francisco Dantas - RN. Fonte: Martins, 2017.

\section{Sítio Furna do Noberto}

É um abrigo sob rocha arenítica que está inserido na Serra da Madalena, situado a $602 \mathrm{~m}$ de altitude e posicionado em alta vertente (Figura 20). Possui concavidade em seu interior de aproximadamente $3 \mathrm{~m}^{2}$, o que permite a sua utilização como abrigo, evitando os registros gravados da exposição direta às chuvas e aos raios solares (Figura 21). No interior do suporte rochoso, foram elaboradas gravuras com a técnica de raspagem e picotagem (Figura 22), sendo observado o predomínio de grafismos com traços geométricos circulares e semicirculares (Figura 23). Os painéis contendo as gravuras ocupam uma superfície aproximada de $30 \mathrm{~m}^{2}$. A orientação do abrigo é NE - SE e a sua abertura voltada para Leste. Este sítio se encontra distante 450 m (direção Norte) dos sítios Congo I, II e III. 


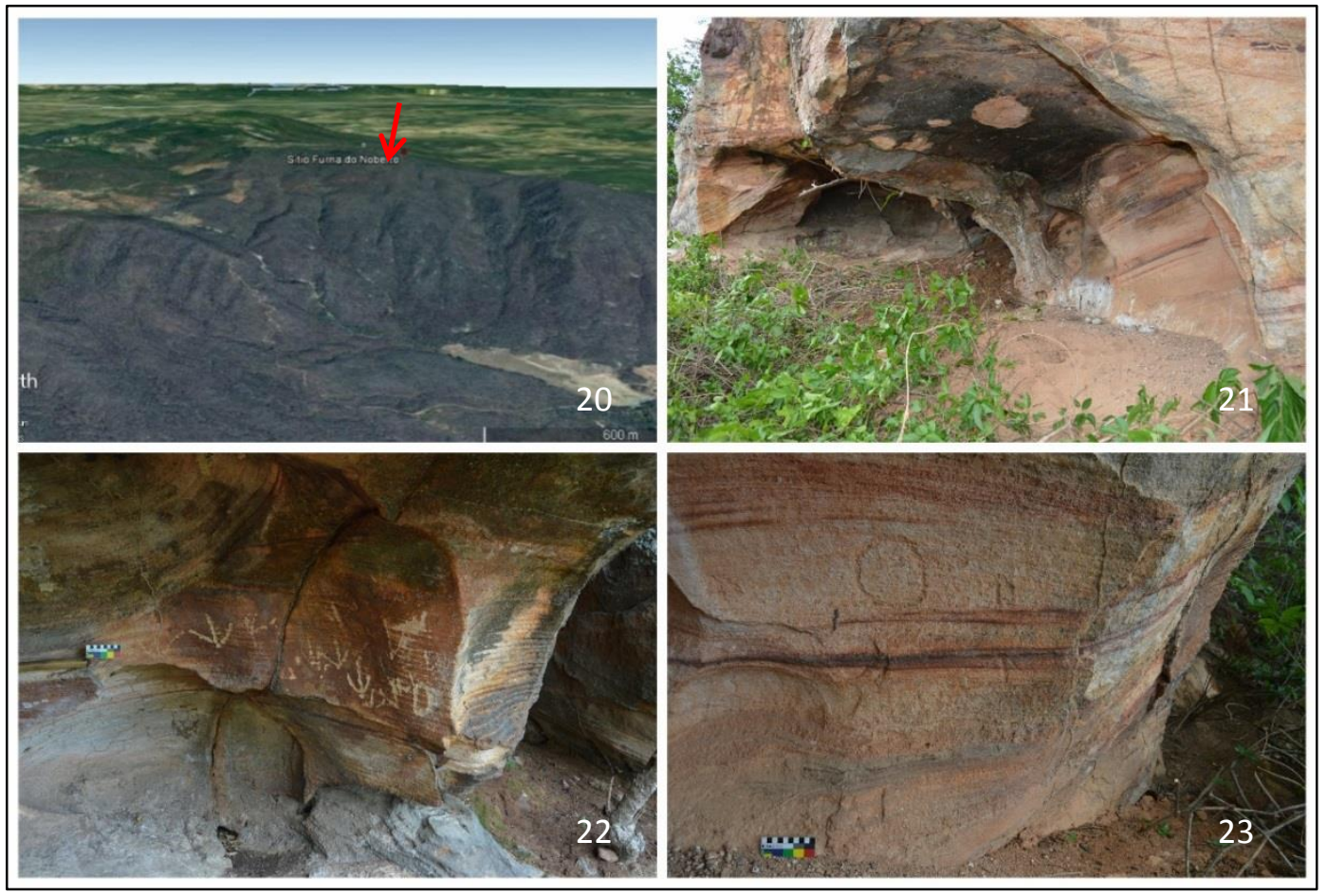

Figuras 20, 21, 22 e 23. Contexto geoambiental em abrigo arenítico em alta vertente: técnicas de execução por raspagem e picotagem; grafismos abstratos; presença de alinhamento de cúpulas- Sítio Arqueológico Furna do Noberto - Serra da Madalena - Francisco Dantas - RN. Fonte: Google Earth, 2017; Martins, 2017.

\section{Sítio Furna do Pelado}

É um abrigo sob rocha arenítica, de difícil acesso, estando inserido na unidade geográfica da Serra de Portalegre, situado a $622 \mathrm{~m}$ de altitude, posicionado em alta vertente (Figura 24). 0 seu interior possui um formato de concavidade, permitindo utilizar a denominação de abrigo, estando livre da incidência direta dos raios solares e das chuvas (Figura 25). No interior desse suporte rochoso, no plano sub-horizontal, foram elaborados vários registros gravados com a técnica de raspagem, com uma tendência verificada de traços retilíneos (Figura 26), linhas côncavas e convexas, além de poligonais (Figura 27).

As gravuras existentes ocupam uma superfície sub-horizontal de $50 \mathrm{~m}^{2} .0$ abrigo possui sua orientação no sentido $\mathrm{N}-\mathrm{S}$ e sua abertura é voltada para Oeste. Não foram identificados sinais de vandalismo, talvez devido a extrema dificuldade de acesso ao local. 


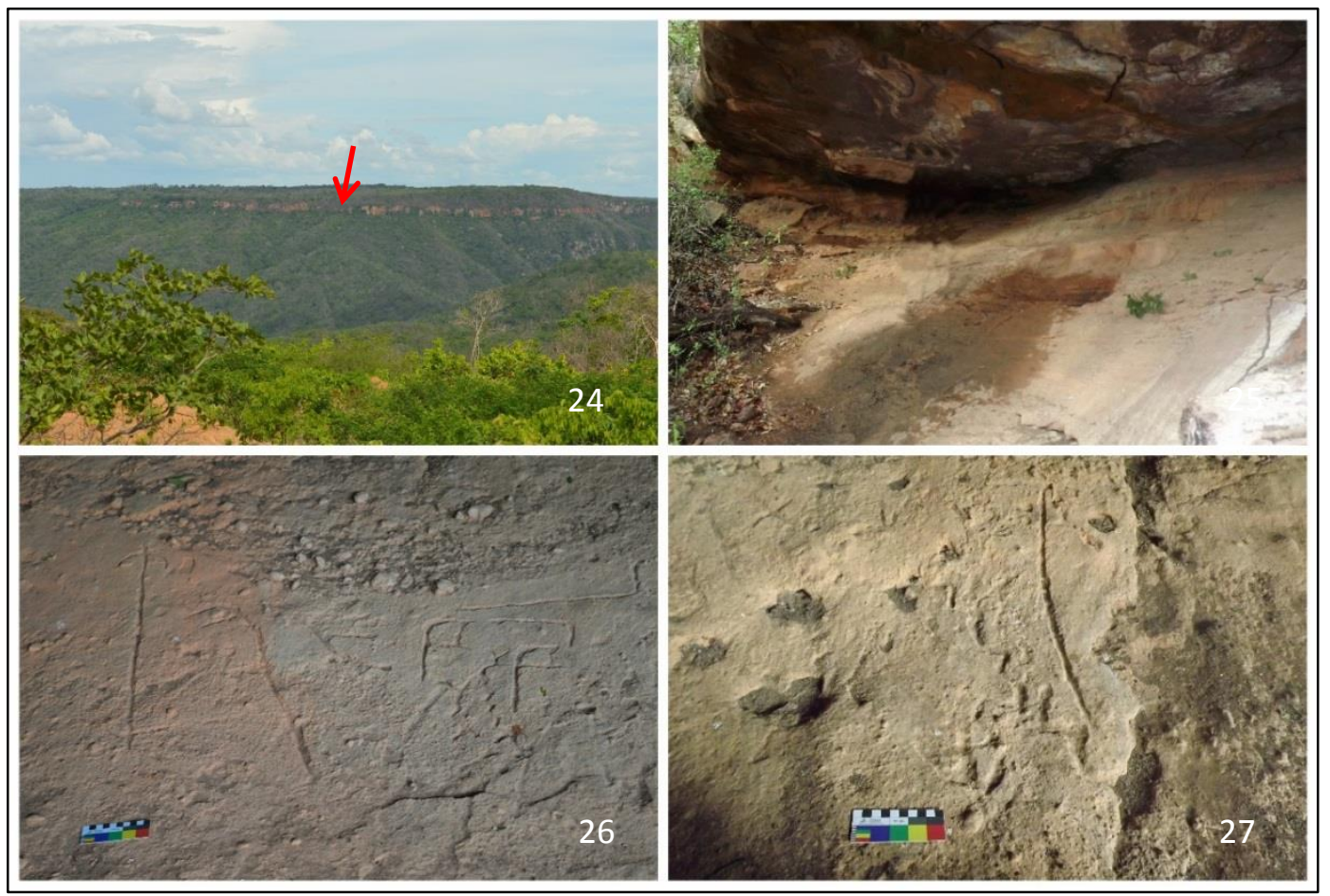

Figuras 24, 25, 26 e 27 - Contexto geoambiental em abrigo arenítico em alta vertente; técnicas de execução por raspagem e picotagem; grafismos abstratos; presença de linhas retas, côncavas e poligonais - Sítio Arqueológico Furna do Pelado - Serra de Portalegre - Portalegre - RN. Fonte: Martins, 2017.

\section{Sítio Pedra do Letreiro}

É um abrigo de rocha arenítica, inserido na Serra de Portalegre, estando situado a $611 \mathrm{~m}$ de altitude, posicionado em alta vertente (Figura 28). Localiza-se na borda de um penhasco (Figura 29), sob um matacão (Figura 30) que exige bastante cuidado de quem pretende visitar o sítio arqueológico. A posição das rochas que compõem o abrigo permitiu a existência de um espaço interno semelhante a uma gruta, com teto abobadado, o que permite a sua utilização como abrigo, evitando a exposição direta as chuvas e ventos. Devido à estreita abertura, o acesso ao interior só é possível rastejando. No suporte rochoso, foram elaboradas gravuras com as técnicas de raspagem e picotagem, com predominância de grafismos abstratos, com traços retilíneos e curvilíneos, além da presença de alinhamentos de cúpules (Figura 31). As gravuras ocupam uma superfície aproximada de $8 \mathrm{~m}^{2}$. Sua orientação é no sentido $\mathrm{N}-\mathrm{S}$ e sua abertura voltada para Leste. 


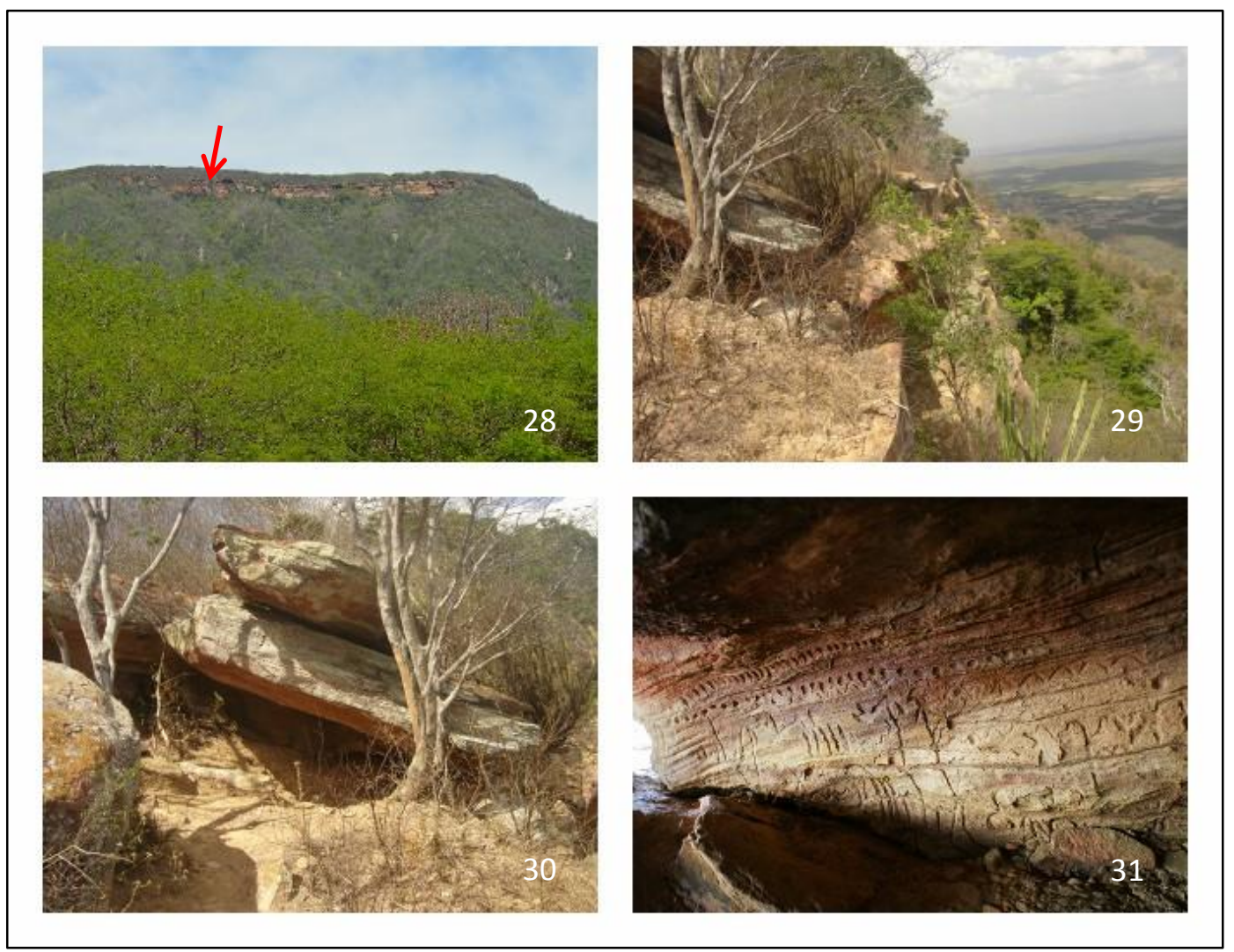

Figuras 28, 29, 30 e 31 - Contexto geoambiental em abrigo arenítico em alta vertente; técnicas de execução por raspagem e picotagem; grafismos abstratos; presença de cúpules - Sítio Pedra do Letreiro Serra de Portalegre - Portalegre - RN. Fonte: Santos Júnior, 2016; Getúlio Moura, 2016.

\section{Discussão dos Resultados}

Com a caracterização dos sítios arqueológicos, foram observadas algumas similaridades nos dois conjuntos da pesquisa relacionadas à inserção no contexto geoambiental e ao perfil gráfico ${ }^{8}$ existente.

Os quesitos geoambientais analisados foram: altimetria, posicionamento do sítio arqueológico no relevo (baixa, média ou alta vertente), litologia do suporte, tipologia de sítio arqueológico (abrigo sob rocha, suporte sub-horizontal) e a distância de fonte d'água mais próxima.

Quanto ao perfil gráfico foram analisados os seguintes quesitos: a técnica de criação (gravuras ou pinturas), a técnica de execução (raspagem, picotagem ou as duas formas em conjunto) e a temática predominante dos grafismos.

Em relação aos quesitos geoambientais (Tabela 1), foi possível concluir que os autores dos grafismos tinham uma clara intencionalidade nas escolhas de locais (abrigos) que tivessem cotas

\footnotetext{
${ }^{8} \mathrm{~A}$ análise do significante rupestre é realizada com a finalidade de estabelecer perfis gráficos para cada sítio, que serão estabelecidos segundo os aspectos: tecnológico, temático e cenográfico. Estes perfis são, portanto estabelecidos em cronologias hipotéticas e constituem o instrumento da análise gráfica. (Pessis, 2008, p. 287).
} 
altimétricas bem elevadas para elaborar seus grafismos, haja vista que as cotas variam entre 602 e $622 \mathrm{~m}$, tendo como média $613 \mathrm{~m}$.

Dessa forma, esse critério foi fundamental para que todos os sítios pesquisados, sem distinção, estivessem localizados em alta vertente em relação ao relevo das duas unidades geomorfológicas (Serra de Portalegre e Serra da Madalena), apesar de existir opções litológicas diferenciadas com abrigos em média e baixa vertente.

Em outro quesito, o tipo de litologia, percebe-se que o suporte em rocha arenítica era a escolha preferencial dos autores, apesar de existir disponibilidade, nessas duas unidades geomorfológicas mencionadas, outros tipos de rocha, tais como o gnaisse e o granito.

Outra preferência unânime observada em outro quesito (tipologia do sítio) foi a escolha somente de locais que funcionassem como abrigos rochosos e que não recebessem diretamente a ação dos raios solares e das chuvas.

Finalmente, no último quesito geoambiental analisado (proximidade com fontes de água), a recorrência persiste novamente, haja vista que todos os sítios arqueológicos, mesmo todos eles situados em alta vertente, ou seja, na "beira de precipícios", se encontram nas proximidades de fontes de água (tipo olho d'água). A furna do Noberto, por exemplo, está situado somente a 185 metros de distância de um olho d'água permanente. 0 sítio Pedra do Letreiro dista da fonte de água $1.750 \mathrm{~m}$.

Esse critério de proximidade dos abrigos com os olhos d'águas (Figura 31), possivelmente está condicionado a necessidade de reposição constante de líquidos durante e após a elaboração dos grafismos, que exigem dispêndio considerável de energia física (notadamente a elaboração das cúpules) exigindo, em contrapartida, um suprimento frequente de água.

Tabela 1. Quesitos geoambientais.

\begin{tabular}{|c|c|c|c|c|c|c|}
\hline Sítio & Alt. & Relevo & $\begin{array}{l}\text { Suporte } \\
\text { Litológico }\end{array}$ & Tipo & $\begin{array}{l}\text { Fonte de } \\
\text { água mais } \\
\text { próxima }\end{array}$ & $\begin{array}{l}\text { Distância do } \\
\text { abrigo para a } \\
\text { fonte de } \\
\text { água } \\
\text { (metros) }\end{array}$ \\
\hline Congo I & $617 \mathrm{~m}$ & Alta vertente & Arenito & Abrigo sob Rocha & $\begin{array}{l}\text { Olho } \\
\text { d'água }\end{array}$ & 450 \\
\hline Congo II & $611 \mathrm{~m}$ & Alta vertente & Arenito & Abrigo sob Rocha & $\begin{array}{l}\text { Olho } \\
\text { d'água }\end{array}$ & 370 \\
\hline Congo III & $616 \mathrm{~m}$ & Alta vertente & Arenito & Abrigo sob Rocha & $\begin{array}{l}\text { Olho } \\
\text { d'água }\end{array}$ & 465 \\
\hline Ancoreta & $616 \mathrm{~m}$ & Alta vertente & Arenito & Abrigo sob Rocha & $\begin{array}{l}\text { Olho } \\
\text { d'água }\end{array}$ & 225 \\
\hline Furna do Noberto & $602 m$ & Alta vertente & Arenito & Abrigo sob Rocha & $\begin{array}{l}\text { Olho } \\
\text { d'água }\end{array}$ & 185 \\
\hline Furna do Pelado & $622 \mathrm{~m}$ & Alta vertente & Arenito & Abrigo sob Rocha & $\begin{array}{l}\text { Olho } \\
\text { d'água }\end{array}$ & 430 \\
\hline Pedra do Letreiro & $611 \mathrm{~m}$ & Alta vertente & Arenito & Abrigo sob Rocha & $\begin{array}{l}\text { Olho } \\
\text { d'água }\end{array}$ & 1.750 \\
\hline
\end{tabular}


Com relação aos quesitos analisados do perfil gráfico de cada sítio avaliado, foi possível averiguar inicialmente, uma uniformidade na escolha na técnica de criação dos grafismos, tendo a técnica de gravuras como um predomínio em todos os sítios, com a inserção isolada da técnica de pinturas em alguns painéis de gravuras, mesmo assim, em um único sítio arqueológico (Ancoreta). Em outro quesito analisado, foi observada a opção dos autores dos grafismos por duas técnicas de execução em todos os sítios arqueológicos: grafismos elaborados com a técnica de raspagem e de picotagem (principalmente as representações cupulares).

Finalmente, em relação à dimensão temática, foi possível constatar certa uniformidade nas representações, pois praticamente, só observam-se grafismos abstratos. A exceção é somente uma gravura zoomorfa inserida no Sítio Congo II.

Uma característica observada foi a ocorrência eventual de sobreposições em alguns painéis gráficos, mas a predominância dos grafismos eram em posições isoladas e distanciados uns dos outros.

Tabela 2. Quesitos técnicos (perfil gráfico)

\begin{tabular}{llll}
\hline Sítio Arqueológico & Tipologia gráfica & Técnica de execução & Temática utilizada \\
\hline Congo I & Gravuras & Raspagem e picotagem & Grafismos Abstratos \\
\hline Congo II & Gravuras & Raspagem e picotagem & Grafismos Abstratos \\
\hline Congo III & Gravuras & Raspagem e picotagem & Grafismos Abstratos \\
\hline Ancoreta & Gravuras e Pinturas & Raspagem e picotagem & Grafismos Abstratos \\
\hline Furna do Noberto & Gravuras & Raspagem e picotagem & Grafismos Abstratos \\
\hline Furna do Pelado & Gravuras & Raspagem e picotagem & Grafismos Abstratos \\
\hline Pedra do Letreiro & Gravuras & Raspagem e picotagem & Grafismos Abstratos \\
\hline
\end{tabular}

\section{Considerações Finais}

Os dados obtidos na pesquisa indicam semelhanças recorrentes em praticamente todos os quesitos geoambientais e quesitos técnicos do perfil gráfico do conjunto de sítios arqueológicos pesquisados.

Essa similaridade indica que os grupos pretéritos que foram os autores desses grafismos adotaram um mesmo tipo de padrão de assentamento, priorizando critérios de escolhas relacionadas ao ambiente que os rodeavam, tais como: posicionamento do sítio no relevo, litologia, tipo de suporte, proximidade da água e utilização do mesmo perfil gráfico. Tendo em vista essas recorrências, é possível que a autoria social desse simbolismo expresso nos sete sítios arqueológicos pesquisados esteja vinculada ao mesmo grupo cronológico. Entretanto, mesmo que tenha sido por grupos humanos em períodos cronológicos diferenciados, as características do mesmo padrão de assentamento persistiram.

A conclusão desse trabalho vai com um alerta para a necessidade de preservação desse patrimônio cultural que já sofreu atos de vandalismo, mesmo estando situados em locais quase inacessíveis. Dos sete sítios descritos nesta pesquisa, quatro deles (Congo I, Congo II e Ancoreta) 
foram atingidos pelo vandalismo, com aplicação de pigmento de cor branca sob as gravuras originais e/ou inscrição de nomes contemporâneos. Isso indica a urgência de medidas mitigadoras dos impactos causados nesses três espaços arqueológicos situados na Serra da Madalena, no atual município de Francisco Dantas-RN.

\section{Referências}

BEBER, M. V. 2004. O sistema de assentamento dos grupos ceramistas do planalto sul-brasileiro: o caso da tradição Taquara/Itararé. Tese (Doutorado em História), Universidade do Vale do Rio dos Sinos, São Leopoldo-RS.

CAMACHO, R. G. V.; DE ALMEIDA, J. E. 2014. Do Diagnóstico Da Bacia Hidrográfica Do Rio Apodi/MossoróRN e a Instalação Do Comitê. Anais do XII Simpósio de Recursos Hídricos do Nordeste, Natal.

CISNEIROS, D. 2008. Similaridades e diferenças nas pinturas rupestres pré-históricas de contorno aberto no Parque Nacional Serra da Capivara-PI. Tese (Doutorado em Arqueologia) Programa de Pós-Graduação em Arqueologia, Universidade Federal de Pernambuco, Recife.

CPRM - Serviço Geológico do Brasil- Projeto cadastro de fontes de abastecimento por água subterrânea. Diagnóstico do município de Francisco Dantas, estado do Rio Grande do Norte / Organizado [por] João de Castro Mascarenhas, Breno Augusto Beltrão, Luiz Carlos de Souza Junior, Saulo de Tarso Monteiro Pires, Dunaldson Eliezer Guedes Alcoforado da Rocha, Valdecilio Galvão Duarte de Carvalho. Recife: CPRM/PRODEEM, 2005.

CPRM - Serviço Geológico do Brasil - Projeto cadastro de fontes de abastecimento por água subterrânea. Diagnóstico do município de Portalegre, estado do Rio Grande do Norte / Organizado [por] João de Castro Mascarenhas, Breno Augusto Beltrão, Luiz Carlos de Souza Junior, Saulo de Tarso Monteiro Pires, Dunaldson Eliezer Guedes Alcoforado da Rocha, Valdecílio Galvão Duarte de Carvalho. Recife: CPRM/PRODEEM, 2005.

FAGUNDES, M. 2008. Uma análise da paisagem em arqueologia - os lugares persistentes. Canindé (MAX/UFS), v. 01, p. 01-11.

GURGEL, S. P. P. 2013. in: Gleydson Pinheiro Albano; Larissa Ferreira, Agassiel de Medeiros Alves. Org. Capítulos De Geografia Do Rio Grande Do Norte. Natal: Fundação José Augusto.

HYDER, W. D.2005. Locational analysis in rock-art studies. In: CHIPPINDALE, C.\& NASH,G.(orgs.) The figured landscapes of rock-art: looking at pictures in place. Cambridge: Cambridge University Press.

ISNARDIS, A.; LINKE, V. 2015. Pedras pintadas, paisagens construídas: a integração de elementos Culturalmente arquitetados na transformação e manutenção. Revista de Arqueologia, v. 23, n. 1, p. 42 59. 
LANATA, J. L. 1993. Evolución, espacio y adaptación en grupos cazadores-recoletores. Revista do Museu de Arqueologia e Etnologia, no. 3, São Paulo: MAE - USP. p.3-15.

MARTIN, G. 2005. Pré-história do Nordeste do Brasil. 4a ed. Recife: UFPE.

MORAES, L. J. 1977. Serras e montanhas do Nordeste Vol. 1. 2ª Edição. Mossoró: Coleção MossoroenseVolume XXXV, 1977

MORAIS, J. L. 2007. Monitoramento arqueológico da reabilitação do oleoduto OSBAT, Km 0 - 32. Relatório final, São Sebastião.

MORAIS, J. L. 2000. Arqueologia da região sudeste. Revista da USP. № 44, pp. 194-217.

MARTINS, A. J. D. A. 2001. História do Município de Francisco Dantas-Aspectos Históricos, Geográficos e Sociais. Natal: Gráfica Sul.

MUTZENBERG, D. S. 2007. Gênese e ocupação pré-histórica do Sítio Arqueológico Pedra do Alexandre: uma abordagem a partir da caracterização paleoambiental do Vale do Rio Carnaúba-RN. Recife: UFPE.

PESSIS, A. M. 2002. Do estudo das gravuras rupestres pré-históricas no Nordeste do Brasil. CLIO série arqueológica, n. 15.

RENFREW, C.; BAHN, P. 1998. Archaeologia: Teorías, Métodos, y Prática. Madrid: Akal.

RIBEIRO, L. Os significados da similaridade e do contraste entre estilos de Arte Rupestre. Um estudo regional das gravuras e pinturas do alto-médio São Francisco. 2006. Tese (Doutorado em Arqueologia). Museu de Arqueologia e Etnologia, Universidade de São Paulo. São Paulo.

SANTOS JÚNIOR, V. 2013. Arqueologia da paisagem: proposta geoambiental de um modelo explicativo para os padrões de assentamentos do Enclave Arqueológico Granito Flores, microrregião de Angicos (RN). Recife: UFPE.

SANTOS JÚNIOR, V. 2008. As técnicas de execução das gravuras rupestres do Rio Grande do Norte. FUMDHAMentos, v. VII.

SILVA, F.A., 1953. Boletim Bibliográfico da Biblioteca Pública Municipal de Mossoró e do Museu Municipal de Mossoró. Ano IV, número 44, Mossoró-RN. 